Biorheology Vol. 15, pp. 399-401.

Pergamon Press Ltd. 1978. Printed in Great Britain.

\title{
ALCOPLEY ART EXHIBIT
}

AT THE MANDEVILLE ART GALLERY, LA JOLLA, CA, USA, 27.8 TO 1.9 .1978 -

AN ACTIVITY OF THE THIRD INTERNATIONAL CONGRESS OF BIORHEOLOGY

\section{Exhibition and Catalogue}

Alcopley's one-man show of forty-five paintings, watercolor-inks, collages, drawings and prints was held at the art gallery of the University of California, San Diego, Mandeville Art Center at La Jolla. The retrospective exhibition covered a period of thirty-one years from 1947 to 1978. It was open to the general public and attracted many visitors including the participants of the Congress and their families.

The Art Exhibit catalogue, consisting of eight pages and printed in black on white, was issued by the Congress. Both outside covers of the catalogue are reproduced in Figs. 1 and 2. The back cover (Fig. 2) is a reproduction of the

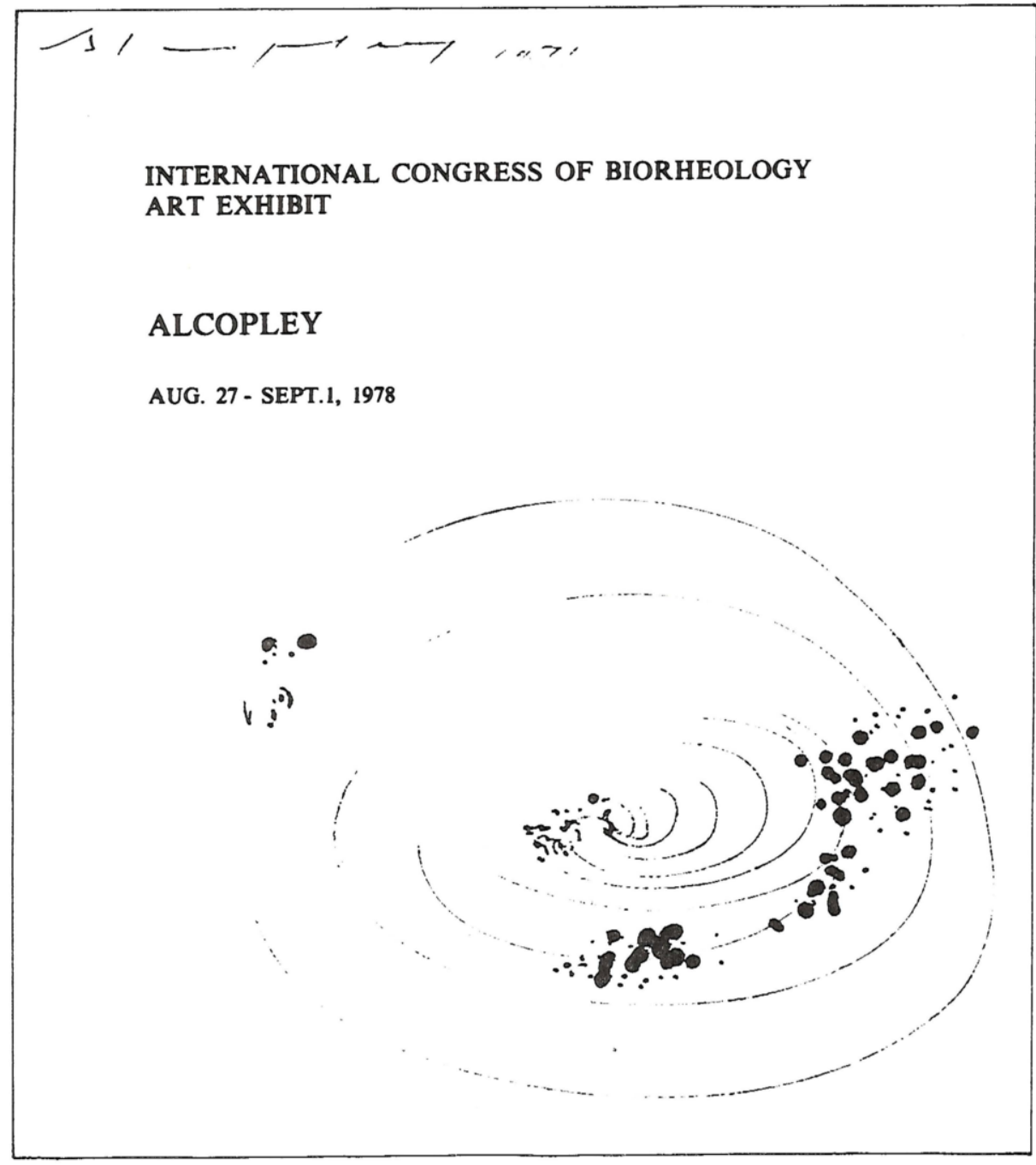

Fig. 1

Front cover of Congress Catalogue containing an ink drawing by L. Alcopley. 


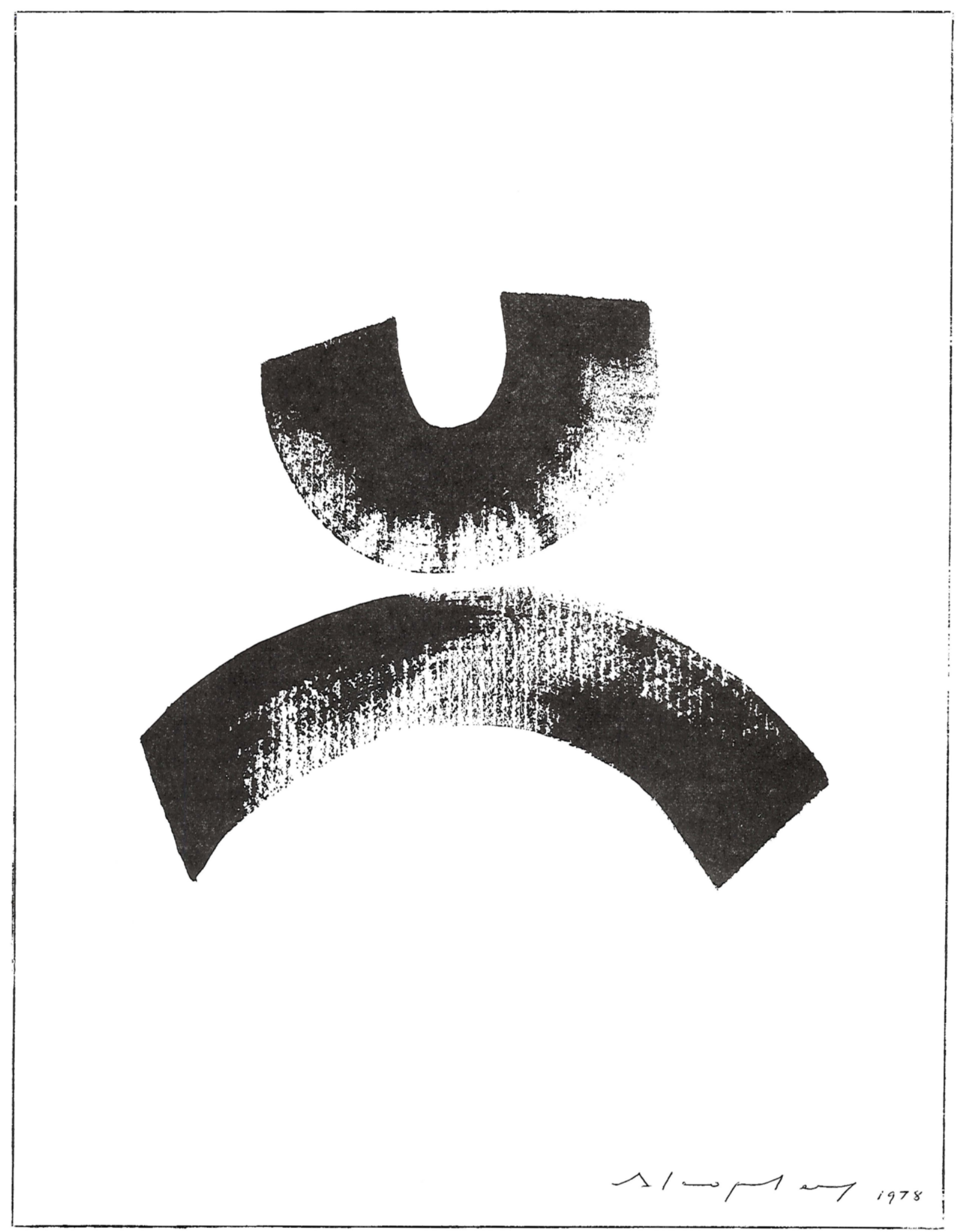

Fig. 2

Reproduction of picture, painted in acrylic by Alcopley upon request of Congress Chairman Y.C. Fung and titled by him "Theme of Biorheology". 
drawing "Theme of Biorheology". There are three other full page reproductions of drawings in the catalogue.

The oil and acrylic paintings varied greatly in format and size. The longest painting, titled "Unfolding" and painted in 1974, was $72 \mathrm{~cm}$ high and 10 meters wide, while the tallest painting, untitled and painted in 1976, was $3.9 \mathrm{~m} \mathrm{high}$ and $94 \mathrm{~cm}$ wide.

Alcopley referred to the pictures in a vertical position as "skyscraper paintings" and to those in the horizontal position as "promenade paintings". His "original thought was to have the vertical pictures along the height of skyscrapers or very tall buildings, and the horizontal pictures or any of its sections as a single band" (L. Alcopley, Leonardo 1, 3-16, 1968). The promenade pictures could be presented as mural paintings or mosaics on walls of hallways of buildings and of pathways on airports. Although the dimensions of both kinds of elongated pictures would remain the same as the pictures on exhibit painted in the studio, their sizes, when applied to very large areas, could become immense.

Most pictures in the exhibit had regular formats from the miniature size of $2 \mathrm{~cm}$ by $1.5 \mathrm{~cm}$ to the largest size of $234 \mathrm{~cm}$ in height and $318 \mathrm{~cm}$ in width. There were four skyscraper paintings and eight promenade paintings. One skyscraper picture, painted in 1956 and mounted in the center of a strip of red felt, $7 \mathrm{~cm}$ in diameter, was $366 \mathrm{~cm}$ high and $3 \mathrm{~cm}$ wide. This picture, 122 to 1 in dimension, if painted on the outside of a skyscraper, for instance, in the rather small width of 1 meter would thus have a height of 122 meters.

The catalogue contained also a Brief Selected List of Alcopley's one-man shows. Twenty-seven of these exhibitions are mentioned. They were held from 1946 to 1978 in USA, France, Japan, Switzerland, Germany, Holland, England, Israel and Iceland. Selections of Museum Collections, 1isting eight museums in six countries, and of group exhibitions in many countries were included.

EDITOR

\section{Catalogue Preface}

In Alcopley science and art unite. He senses form, structure, and movément in science, he presents the senses of movement, form and structure in drawings. Who is he? He is the originator of the word "Biorheology". What is he? He is a professional artist in New York. As a scientist, he is called A.L. Copley. He was the first President of the International Society of Biorheology, and the Editor of the journals "Thrombosis Research" and "Biorheology". He is currently Director of the Laboratory of Biorheology and Professor of Life Science and Bioengineering at Polytechnic Institute of New York in Brooklyn. For his scientific contributions he was awarded the Poiseuille Gold Medal by the International Society of Biorheology. As an artist, he received his early training in Dresden, but was mainly self-taught. He was a member of Stanley William Hayter's Atelier 17, New York, a founder of "The Club" in New York, and an initiator of the exhibition "l'encre de Chine dans la calligraphie, et l'art Japonais contemporain". He is a member of American Abstract Artists, and of Groupe Espace, Paris.

I have always admired him both as a scientist and as an artist. We know there is harmony in arts and sciences, but rarely have the opportunity to demonstrate it. By exhibiting his art while he participates in a scientific meeting, we offer an opportunity for everyone to figure out the relationship between art and science.

This exhibition at the Mandeville Art Gallery of the University of California at San Diego in association with the Third International Congress of Biorheology has the enthusiastic support and financial assistance from Chancellor William D. McElroy. All the preparations of the Congress and the exhibition were done by our enthusiastic staff and students of Bioengineering at UCSD. To all of them, and to the artist himself, I wish to register my sincere thanks.

Y. C. Fung

Chairman, Biorheology Congress 